\title{
Mission to Mars: Connecting Diverse Student Groups with NASA Experts
}

\author{
Tara Polsgrove ${ }^{1}$ and David Jones ${ }^{2}$ \\ NASA MSFC Advanced Concepts Office ED04, Huntsville AL, 35812 \\ Leslie Sadowski-Fugitt ${ }^{3}$ and Nicole Kowrach ${ }^{4}$ \\ Museum of Science and Industry, Chicago, IL 60637
}

\begin{abstract}
The Museum of Science and Industry in Chicago has formulated an innovative approach to inspiring the next generation to pursue STEM education. Middle school students in Chicago and at nearby Challenger Learning Centers work in teams to design a mission to Mars. Each mission includes real time access to NASA experts through partnerships with Marshall Space Flight Center, Johnson Space Center, and the Jet Propulsion Laboratory. Interactive videoconferencing connects students at the museum with students at a Challenger Learning Center and with NASA experts. This paper describes the approach, the results from the program's first year, and future opportunities for nationwide expansion.
\end{abstract}

\section{Introduction}

$\mathrm{N}$ ASA has long had the mandate to inspire and help to educate the next generation. NASA investments in education programs and support to educators around the country serve to strengthen NASA and the Nation's future workforce, attract and retain students in science, technology, engineering and mathematics, or STEM, disciplines, and engage Americans in NASA's mission. The program "Mission to Mars: An Urban/Rural Collaborative to Inspire NASA's Next Generation" brings together the Museum of Science and Industry (MSI), Chicago; the Challenger Learning Centers (CLC) in Woodstock and Bloomington/Normal, IL; the NASA Marshall Space Flight Center (MSFC); the Jet Propulsion Laboratory (JPL); the NASA Johnson Space Center (JSC); and Chicago Public Schools to create an informal, live distance learning program that broadens youth engagement with STEM education and learning about NASA's research and goals for students in grades six through eight.

The above-named partners have jointly developed three 90-minute Mission to Mars scenarios designed for informal settings with NASA's support. The three scenarios reflect the goals and activities of the Science and Human Exploration and Operations Mission Directorates, and spotlight the research being conducted at specific NASA Centers. In each scenario, students work together to design a spacecraft focused on Mars exploration during a field trip to the Museum or a Challenger Learning Center. Pre- and post- field trip curricula ensure that students get the maximum impact from their experience. One of the unique aspects of this program is that students gain the opportunity to videoconference and interact with NASA experts during their mission. Mission to Mars was designed to appeal to under-resourced students, add substantially to middle school education in the earth and space sciences, and create new alliances between formal and informal educators in inner city and rural areas while linking them with the NASA Center's own educational outreach initiatives.

This paper presents an overview of the program, mission curriculum and implementation, a summary of feedback from students, teachers, and NASA participants, and ideas on how this program could be replicated to reach more students across the country. It is the authors' hope that space professionals reading this paper will help to spread this program across the country and participate where possible.

\footnotetext{
${ }^{1}$ Aerospace Engineer, Advanced Concepts Office, ED04, NASA MSFC, Huntsville, AL 35812, non-member.

${ }^{2}$ Aerospace Engineer, Advanced Concepts Office, ED04, NASA MSFC, Huntsville, AL 35812, non-member.

${ }^{3}$ Senior Coordinator, Interactive Videoconferencing, Mission to Mars Program, Museum of Science and Industry, Chicago, IL, non-member.

${ }^{4}$ Director of Teaching and Learning and Project Manager, Mission to Mars Program, Museum of Science and Industry, Chicago, IL non-member.
} 


\section{Background}

The Museum of Science and Industry and partners won a competitive NASA grant (Competitive Program for Science Museums and Planetariums, CP4SMP) in 2010.1 After curriculum and facility development the first student engagement began in the fall of 2011. During the 2011-12 school year 16 missions were conducted reaching over 1000 middle school students. The 2012-13 school year will have twice the number of missions and the hope is to grow the number of missions performed each year after. The NASA grant performance period is through June of 2014, but the Museum intends to sustain the program by continuing to offer missions beyond the grant period.

The project goals are to:

- Implement new educational linkages via an interactive videoconferencing platform between MSI, a major inner city public school district, schools serving low income rural and suburban middle school students, and, initially, two Challenger Learning Centers (CLCs).

- Design, evaluate, and launch three programs that showcase research at NASA Centers.

- Promote learning about NASA's space missions and enrich middle school curricula with experiences and challenges that inspire youth to pursue careers in NASA-related STEM.

- Develop a broad dissemination plan with assistance from CLC National to distribute all materials regionally and nationwide and promote project replication among science centers, CLCs, school districts, NASA Centers, and other institutions of informal education.

The Mission to Mars program has been strategically developed to focus on the following three audience impacts for middle school students in grades 6-8 in Chicago Public Schools particularly inner city, rural as well as suburban under-served youth: 1) exploring STEM education with a focus on NASA research, missions, goals and aims indepth; 2) gaining skills in searching online resources, communicating effectively with their peers and adult role models, practicing 21 st century science and technology skills, and ; 3) working collaboratively to tackle many of the same challenges that NASA scientists are confronting themselves in the effort to travel to and inhabit Mars. Most of the student target audience will attend schools where at least 50\% of the students receive free or reduced lunch through the National School Lunch Program.

\section{Implementation}

Team members at MSI worked with each of the NASA partners to develop a mission or activity to engage the students that was similar to what the experts would do in their jobs. Each mission represents a different aspect of possible future missions to Mars; designing launch vehicles needed to send payloads to Mars, landing on Mars, and living on Mars. Teachers select the mission for their class and receive preparation materials from MSI. Prior to mission day students make comparisons between Mars and Earth, learn about the current status of Mars exploration, and prepare a presentation about their class and school to share with the students at their partner CLC. When they arrive, students at MSI and students at one of the participating Challenger Learning Centers are broken into teams to solve the problems presented by their mission scenario. Once they've completed their activities they share results with each other and with experts via live video conference and have the opportunity to ask the experts questions.

\section{A. Mission Scenarios}

\section{Scenario One: Planning A Mission To Mars}

In Scenario One, Planning a Mission to Mars, students select a payload to send to Mars and then design a launch vehicle to get it there. Student teams work together to determine a scientific objective which leads them to choose a particular type of spacecraft: orbiter, lander or rover. Then design a launch vehicle capable of lifting that spacecraft and sending it on its way to Mars. Students are presented with several options for boosters, core stage, and upper stage, each with different thrust levels and total weight. To have a successful launch they must ensure that the thrust of the core stage and boosters is greater than the weight of the total stack including payload and shroud. They must also ensure that the thrust remains greater than the stack weight when the boosters separate and the core stage propellants are $50 \%$ consumed. They continue to calculate the thrust to weight ratio at each staging point along the trajectory with no thrust to weight constraints.

Piloting of Scenario One began on October 26, 2011, in partnership with Marshall Space Flight Center. Between late October and the last run of Scenario One on February 1, 2012, the program reached approximately 220 middleschool students at off-site locations, and approximately 210 middle school students participating from MSI. All of the scenarios are continuously developing and improving, and it is hoped that in the 2012-13 school year this scenario will include some simplified use of the rocket equation and the relationship of delta $\mathrm{V}$ to flight time from the Earth to Mars. 


\section{Scenario Two: Landing a Mission on Mars}

During this mission at the Museum and CLC, students participate in activities that simulate selecting a landing site, landing a rover and exploring the physical attributes of Mars. Students at MSI and the CLCs explore geological processes that shape planets, perform chemistry experiments on simulated Martian soil samples and explore the physics of light and reflectance through a set of hands-on activities. They then work together with their partners at a distance to determine which instruments to include on an exploratory rover. Piloting of Scenario Two, in partnership with the Jet Propulsion Laboratory, began in February 2012 and concluded on April 11, 2012.

\section{Scenario Three: Human Habitation On Mars}

During this session at MSI and the CLCs, students deliberate over building a long-term base on Mars, and consider how resources such as food, water, atmosphere, and energy will be produced, procured and allocated. Participants balance pros and cons of different space suit materials and use their knowledge of the Mars terrain and atmosphere to design a base on the planet. Piloting of Scenario Three, began on April 25, 2012, in partnership with the Johnson Space Center and concluded on May 9, 2012.

\section{B. Team Collaboration}

To solve the various problems in the mission scenarios, students at each location are divided into small working groups with specific roles for each individual: Leader, Manager, Communicator and Recorder. See Figure 1. This is an introduction to the way the experts work, solving complex problems in interdisciplinary teams. While the timeframe for the mission, 90 minutes, is not enough to give the students a full appreciation of concurrent engineering or multiple design iterations going on simultaneously, they get a collaborative experience without being overwhelmed. Future plans for the 2012-13 school year include providing the teams at MSI and the Challenger Learning Centers with iPads that they can use to communicate with their counterparts. So Team A at MSI can collaborate with Team A at the CLC for example using a dedication web-based Mission to Mars application.

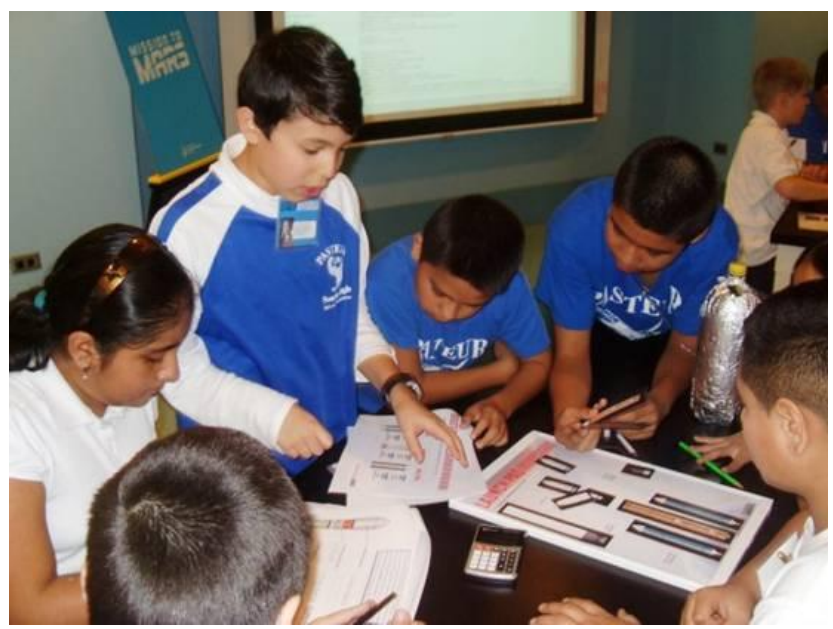

Figure 1. A team of students working on their launch vehicle design, Scenario 1.

\section{Expert Interaction}

NASA experts appear live for 30 minutes via videoconference to discuss the students' challenges and results, while discussing experiences from prior missions conducted by NASA and sharing stories about their own paths to working at NASA. Figure 2 shows an expert answering a question by a student at the Challenger Learning Center in Normal IL. Back in school after the mission, students can continue learning through inquiry-based collaborative learning projects and query NASA websites further for career and mission information. 


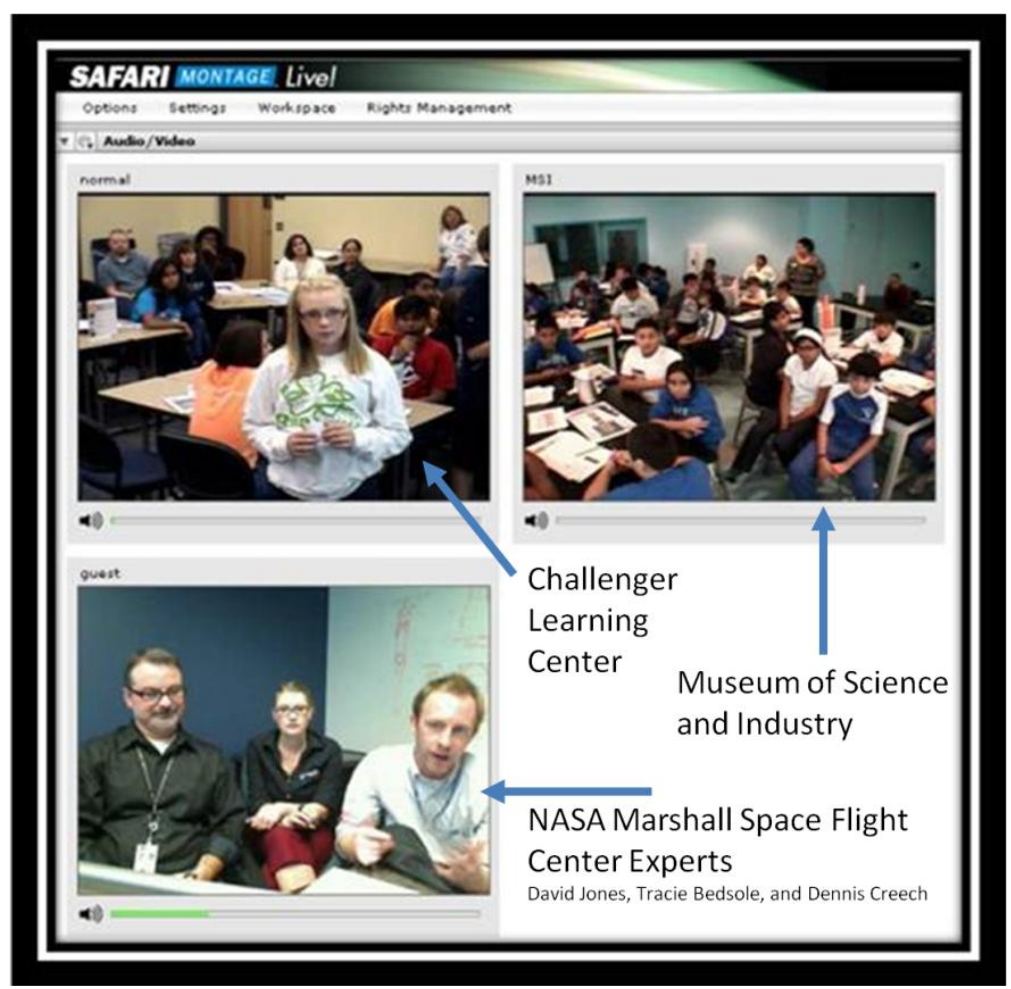

Figure 2. Students interacting with experts via video conferencing software.

\section{Results}

Even in its pilot year this program is already showing significant positive impact on students and teachers. Measuring the effectiveness of this program is critical to continuing and increasing that success. During the pilot year, pre- and post-mission surveys were developed for students and teachers by MSI Research and Evaluation team. Feedback from the grant partners is also sought and taken into account to continuously improve the program.

\section{A. Survey of Teachers and Students}

Surveys and observations of students and teachers before and after each mission assessed the knowledge of NASA missions, attitudes towards science and engineering, and potential career interests of the students. Preliminary results of the pre- and post-program instruments showed that students tended to move away from speculative statements about NASA experts and towards more concrete statements about those experts' actual job roles and responsibilities. Also, observations of the Missions show that students articulated independent solutions to scientific questions in four-fifths of the observed Missions, and that scientific data was shared between participants across program sites in more than half of the observed Missions.

In addition to the surveys, teachers often shared anecdotal stories of how the experience influenced individuals in their class. Observers noted that students became most engaged while speaking with the experts. One teacher told program facilitators that one of her students who struggled in school told her that he wanted to work hard and do what it would take to go into a STEM field.

\section{B. Partner Feedback}

Full partner meetings occur at least twice a year. Anecdotal evidence of the programs impact is shared including any observed opportunities for improvements. For example the staff at the Normal CLC reported that students have been very engaged in the program, and sometimes the discussions with experts run long because students are so interested and excited by the conversations. Students particularly seem to enjoy hearing what the NASA scientists were like as kids themselves. The team at the Woodstock CLC reported that the NASA experts have been very patient with the students, providing encouragement when students become shy, nervous, etc. The students at Woodstock very much enjoy talking to the experts.

Feedback from the volunteers at MSFC was positive regarding MSIs role in preparing the volunteers with tips for speaking with middle school students. Expert participants indicated speaking to the students was a positive 
experience and they appreciated hearing the feedback on the impact of the expert interaction portion of the mission. The expert volunteers really enjoy the students' questions, even when the questions are unexpected. One scientist mentioned that his favorite question a student asked was, "Would you need new lungs (lungs that process carbon dioxide) to breathe on Mars?"

For the 8 missions conducted with MSFC volunteers, 3 of the experts participated in each mission from a volunteer pool of 14. This resulted in an average time commitment of less than an hour per person over a portion of the school year. Commitment in this program is not overly burdensome even as the number of missions is expected to double in the year ahead and stretch across the entire school year. JPL and JSC participants had similar experiences, and all of the missions were executed successfully.

\section{Opportunities for Growth}

This activity is part of a NASA grant that continues through the year 2014. Near-term program growth is already charted. MSI, and its CLC and NASA partners are excited to think about the possibility of expanding this successful model across the country.

The MSI-led team is gearing up for a 2nd year of missions to begin in September of 2012 and is expected to reach more than 2,000 middle school students. Each of the partner centers will double the number of sessions supported to 16 for MSFC, 8 for JPL and 8 for JSC. In the 2013-14 school year it is anticipated that a total of 45 missions will be conducted at an even split between the three participating NASA centers and reaching nearly 3,000 students. See figures 3 and 4.

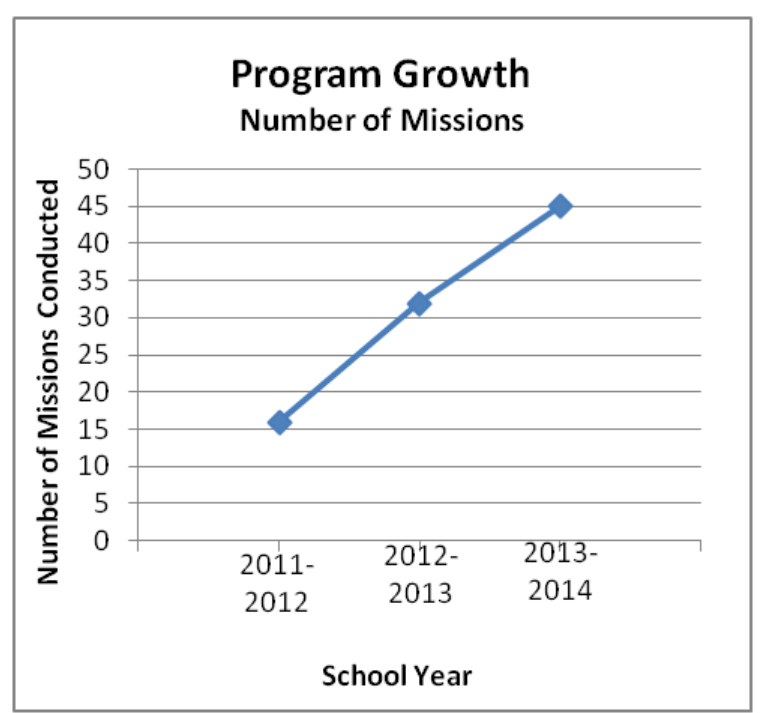

Figure 3. Anticipated Program Growth In Number of Missions Conducted by Year

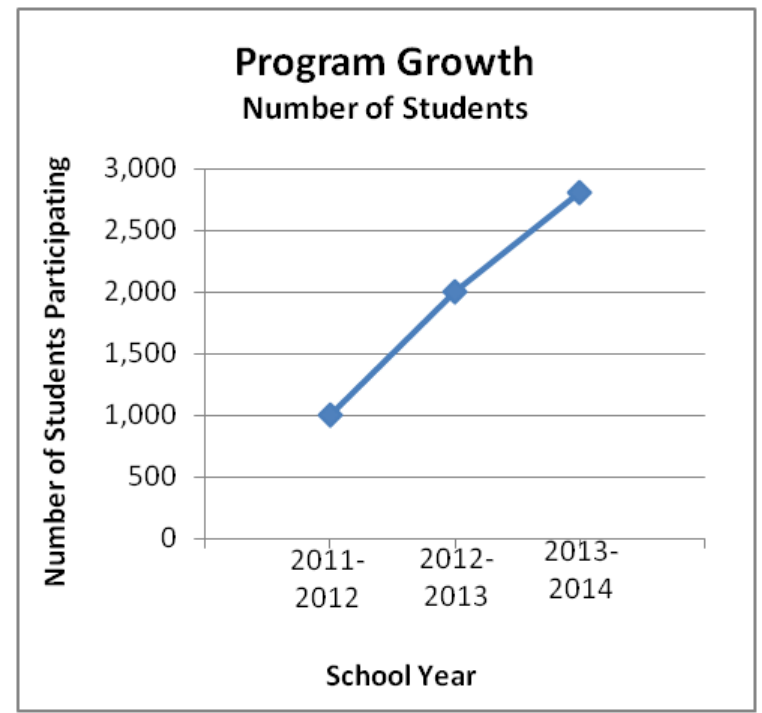

Figure 4. Anticipated Program Growth In Number of Students Participating by Year

One of the great values of this program is that by using easily accessible IP-based videoconferencing, the program can be duplicated beyond the Illinois region and across the country. In the next year MSI will begin working on a regional dissemination plan, and once the mission scenarios mature and stabilize MSI will be able to share the program content and materials with other organizations. One example of how this model could expand would be through the existing Challenger Learning Center partner. These centers promote education about space and exploration and are located across the country and internationally (see figure 5). They are often partnered with science centers, museums, universities and schools, making the adoption of the Mission to Mars outreach program as it currently operates an attractive, and realistic, option. Of course there are many more museums, science centers, academic institutions, and other organizations across the country that could have great success with this model as well. 


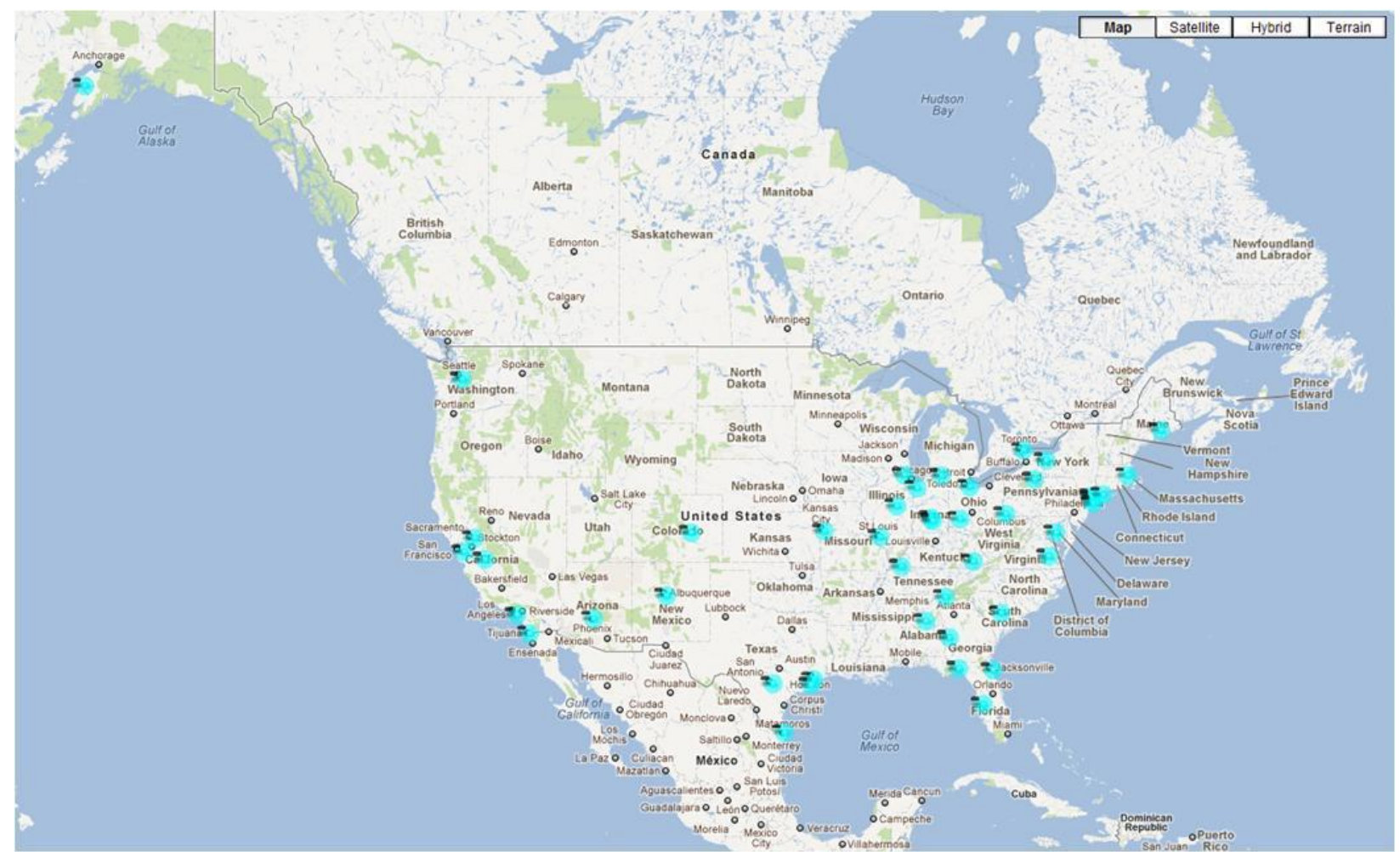

Figure 5. Challenger Learning Center locations across the US. ${ }^{2}$

The other key component of expansion is a fresh supply of industry experts willing to donate a small portion of their time to inspire the next generation. At some point the existing partner NASA centers, MSFC, JPL, and JSC will reach their threshold of capacity to support. That said there are other NASA centers, and many private companies whose contribution to space exploration has the capacity to inspire. See figure 6 for the locations of NASA centers across the US and their respective responsibility areas for providing speakers and supporting outreach activities.

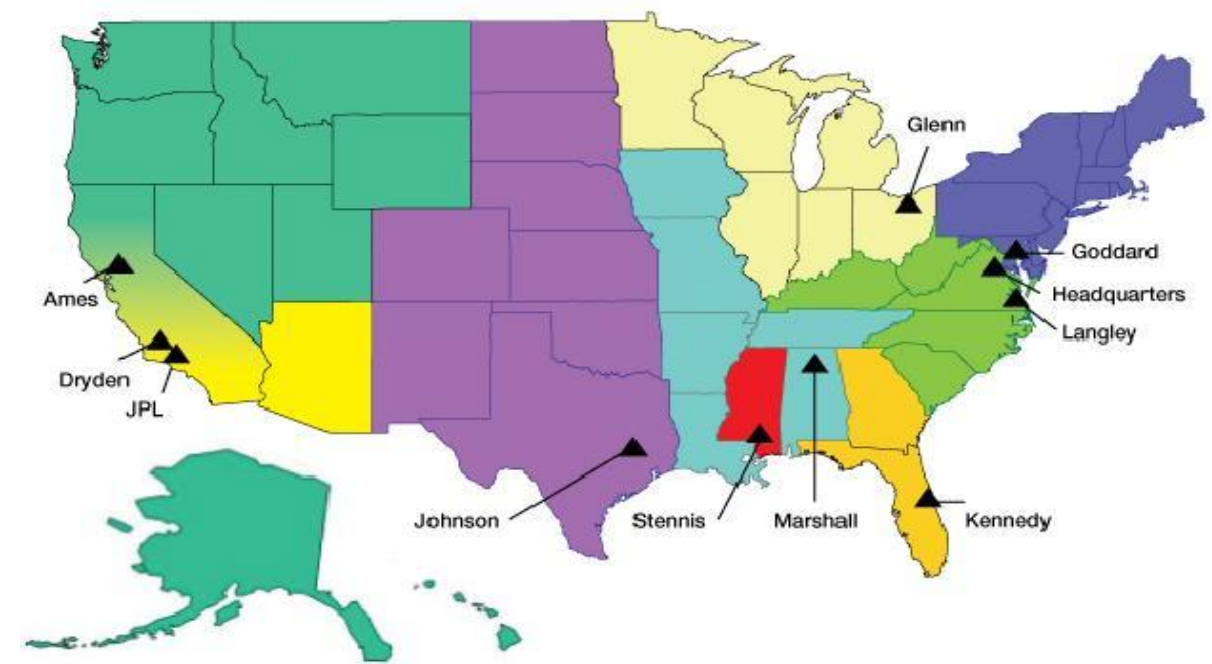

Figure 6. NASA center responsibility split for providing outreach speakers. ${ }^{3}$ 


\section{Conclusions}

The Mission to Mars program provides an exciting new way to engage students in NASA's missions and inspire them to continue their STEM education. Surveys and observations indicate that students knowledge of NASA missions and careers increases, their attitudes about whether STEM careers are interesting improves, and in many cases their self confidence about whether they have what it takes to be a scientist or engineer improves as a result of this program. Videoconferencing with space professionals is a key component of the program and allows space professionals to reach beyond their local school districts to students who may have less direct access to NASA or space-related outreach opportunities. There are many possible avenues to expand or duplicate this type of program at locations around the country where many more of our next generation can be educated and inspired.

\section{References}

\footnotetext{
${ }^{1}$ Mosena, David; Ingram, Andrea, "Mission to Mars: An Urban/Rural Collaborative to Inspire NASA's Next Generation," Competitive Program for Science Museums and Planetariums (CP4SMP), Grant \# NNX10AD93G

${ }^{2}$ Challenger Learning Center US Locations, http://www.challenger.org/clc/network.cfm, cited 8/21/2012

${ }^{3}$ NASA Center Assignments by State, http://www.nasa.gov/about/speakers/nasa-state-assignments.html, cited $8 / 21 / 2012$
} 
Mission To Mars

Connecting Diverse Student Groups

with NASA Experts

Tara Polsgrove \& David Jones

NASA Marshall Space Flight Center, Huntsville, AL

Leslie Sadowski-Fugitt \& Nicole Kowrach

Museum of Science and Industry, Chicago IL 


\section{NAsA Mission to Mars: Background}

- A multi-year education/outreach activity led by the Museum of Science and Industry in Chicago for middle school students

- Partners:

o Chicago Public Schools,

o Challenger Learning Centers in Normal and Woodstock Illinois,

- NASA MSFC, JPL and JSC

- NASA Grant awarded in 2011

- MSFC Involvement coordinated MI5510ח through Tammy Rowan

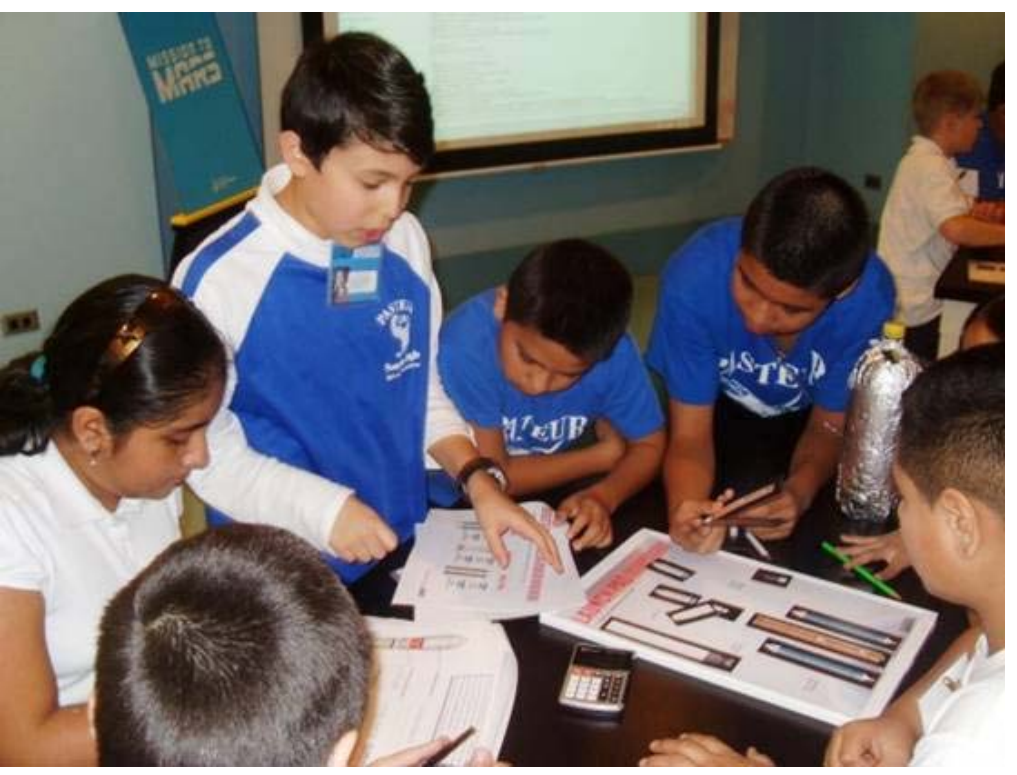


- Students from 2 schools connect through videoconference on mission day during a field trip to the Museum of Science and Industry or a Challenger Learning Center

- Students collaborate to design one of 3 vehicles for a Mars mission:

- Launch Vehicle (MSFC),

- Mars Rover (JPL), or

- Mars Habitat (JSC).

- Pre and Post field trip curriculum is part of the mission

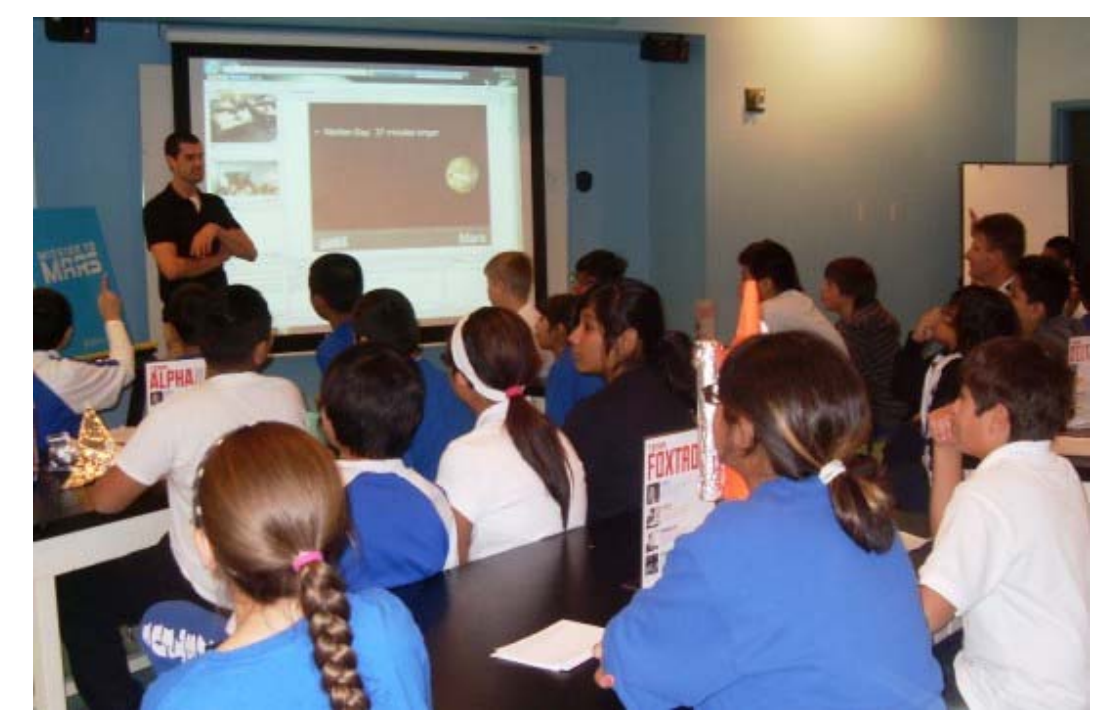




\section{NASA Diverse Student Groups}

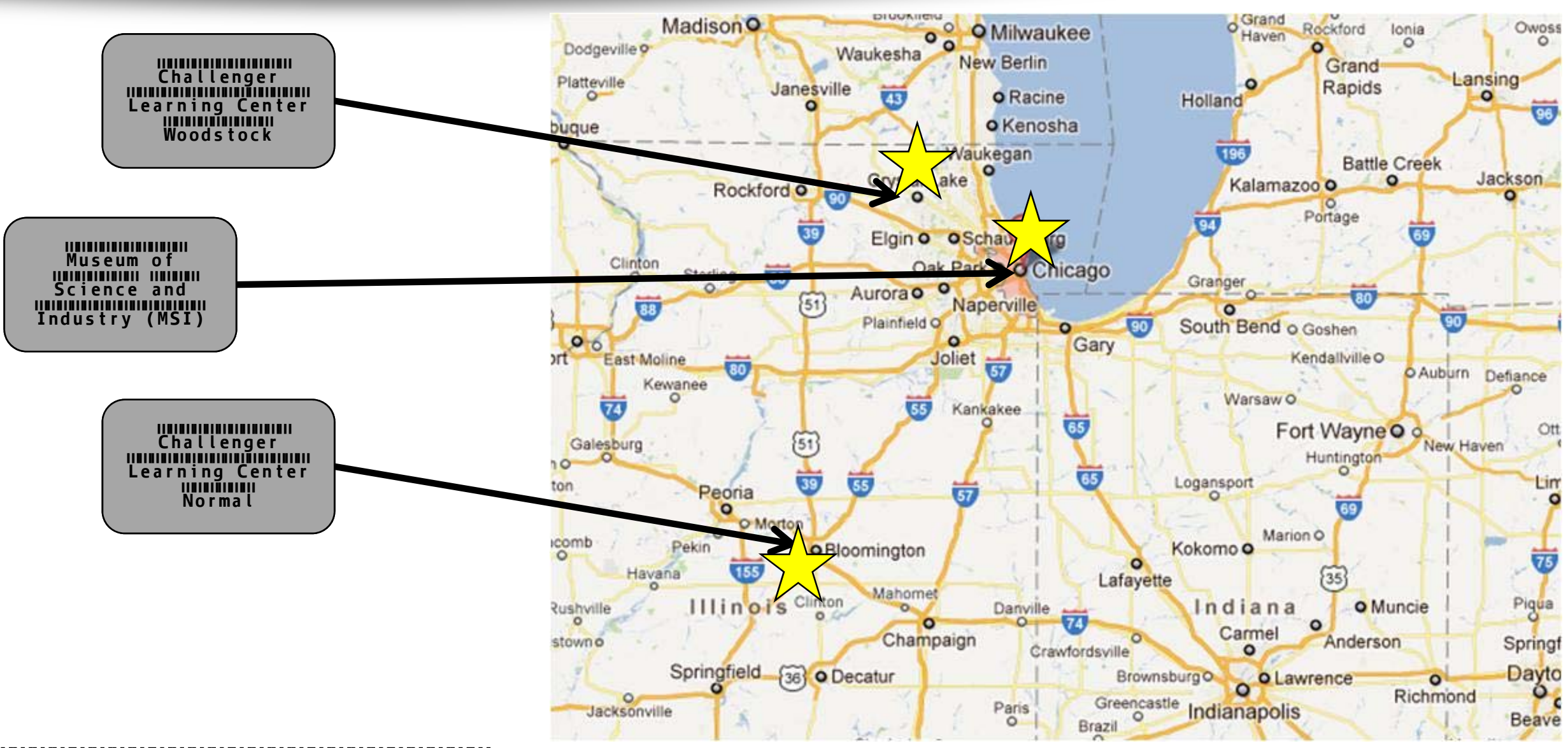

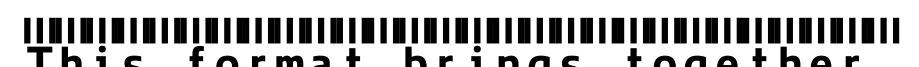

Th s format brings together

students from diverse urban and

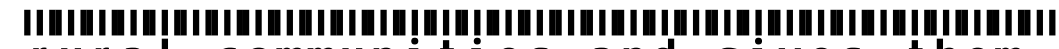

rural communities and gives them

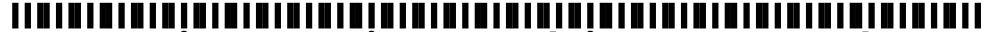

experience in working together

IIII!!IIIIIIIIIIIIIIIIIIIIIIIII

using technology 


\section{Launch Vehicle Design}

- Students stack various launch vehicle stages together and assess

- lift off thrust to weight ratio $<1$

- Thrust to weight $<1$ at booster separation and subtracting half of the propellant mass of the core stage

- Thrust to weigh unconstrained at remaining events

\section{BDOSTER ENGINES ||||||||||||||||||||||||||||}

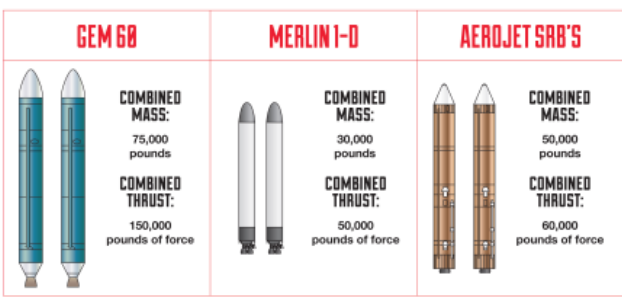

Mำ
5HROUD/PAYLDAD IIIIIIIIIIIIIIIIIIIIIIIIIII

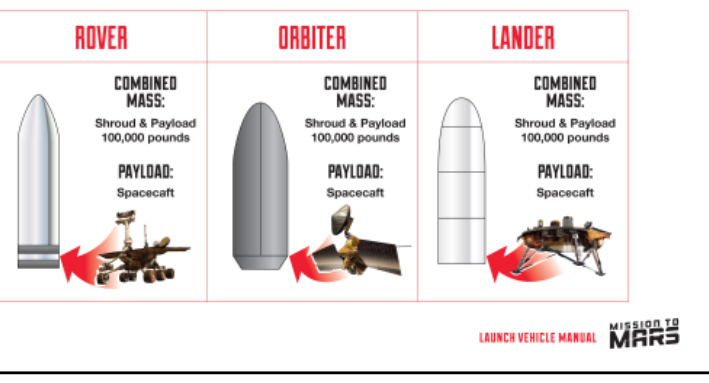

UPPER STAGE ENGINES IIIIIIIIIIIIIIIIIIIIIII

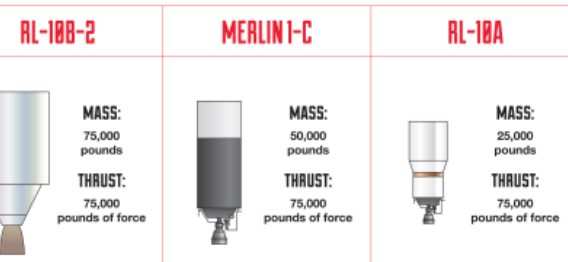

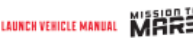

MAIN ENGINES IIIIIIIIIIIIIIIIIIIIIIIIIIIIIIIII

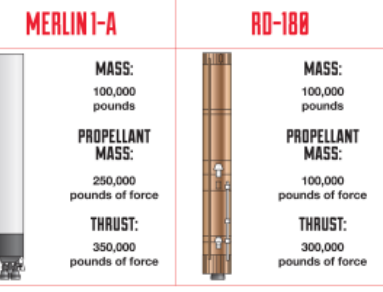


NASA SAFARI Video \& Voice over IP Interaction

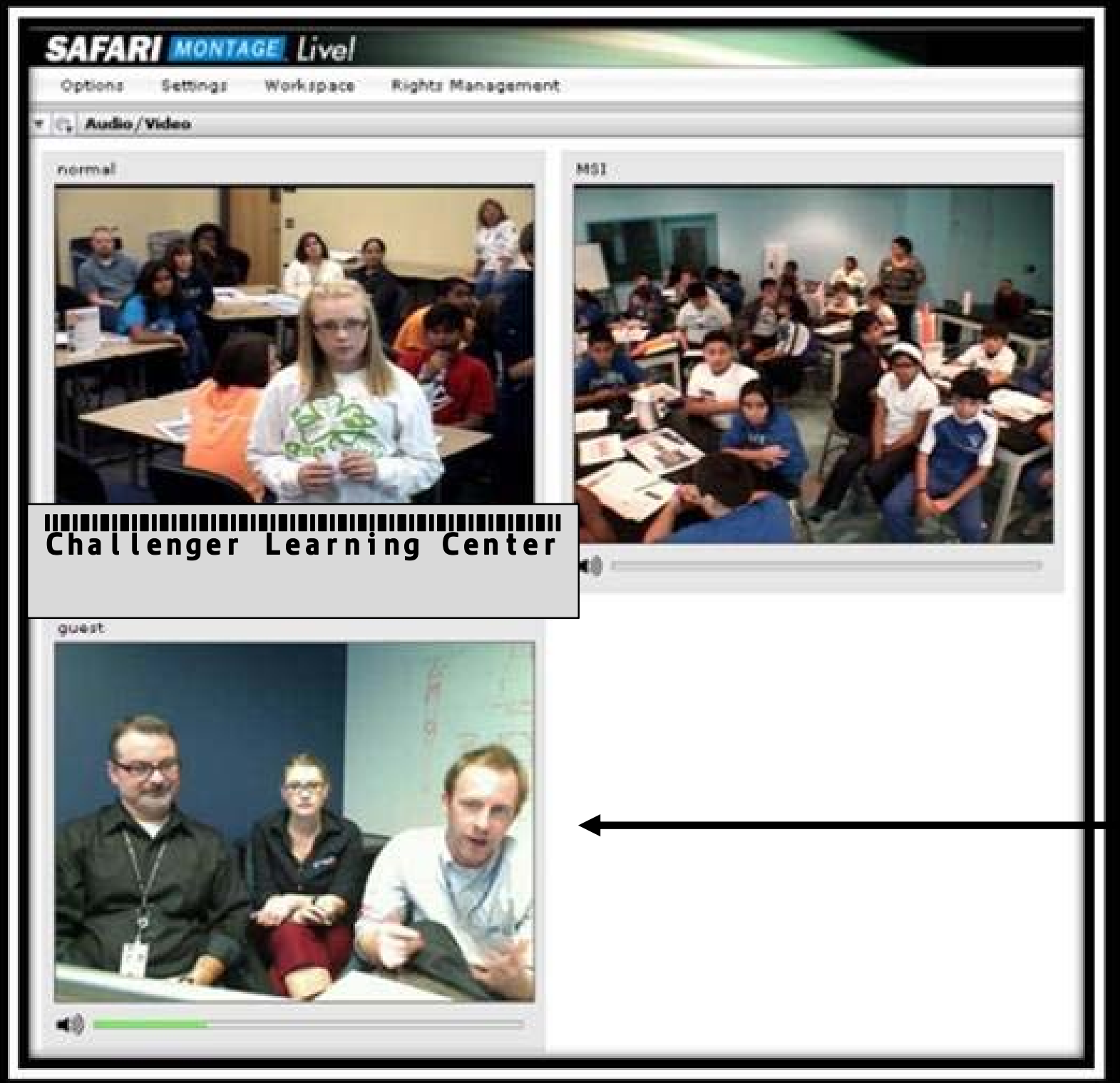

minnm

Museum of science and IIIIIIIIIIIII

Industry

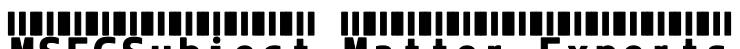

MSFCSubject Matter Experts

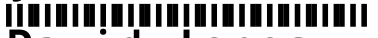

David ones

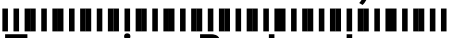

Tracie Bedsole,

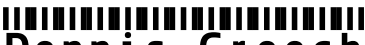

Dennis Creech

Volunteer pool

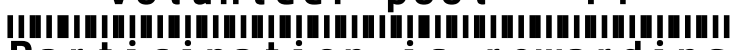
Participation is rewarding 


\section{Naga Student Teams}

- Groups are broken out into 4 person teams for design exercises, each person has an assigned role

- Leader,

- Manager,

- Communicator and

- Recorder

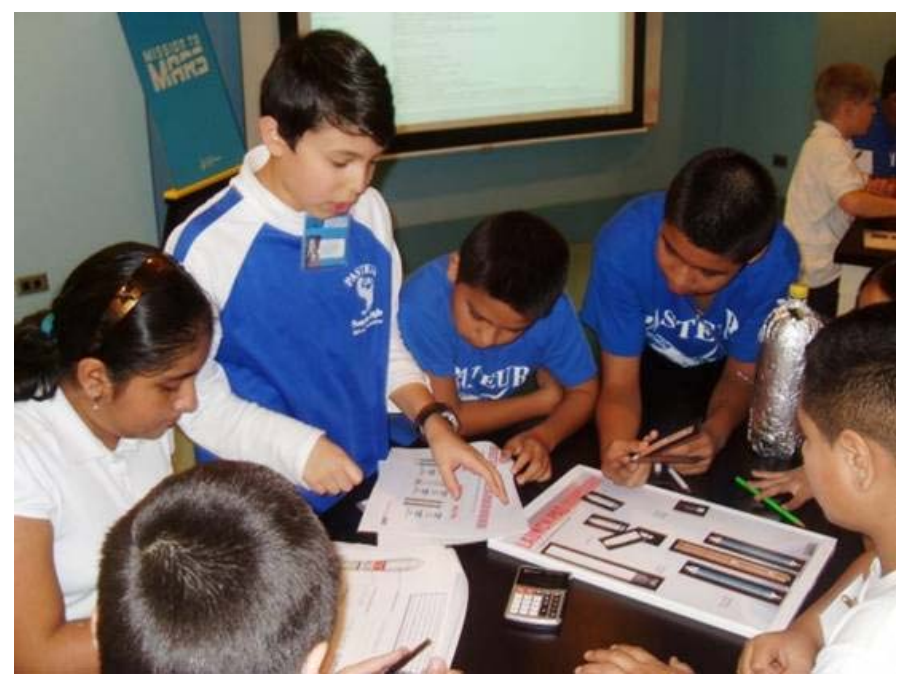

- This is an introduction to collaborative engineering.

- NASA experts talk about their roles on our concurrent engineering teams and how this relates to the students' activity 


\section{Program Results to Date}

- Pre and Post mission surveys of teachers and students have been developed. Observers are in the rooms as well.

- Results so far:

- Students have a much better understanding of NASA missions and the jobs that NASA engineers do after participating

- Students enjoyed interacting with students from other schools

- Students became the most engaged in the activity when talking to NASA experts

- Students seemed to most enjoy hearing what the NASA experts were like when they were in middle school.

- Inspiring students to pursue STEM careers is about the exciting work, but also getting them to see themselves as capable of contributing. 
The 2011-12 Pilot year included 8 missions with MSFC

16 missions total were conducted the first year with MSFC, JPL, and JSC
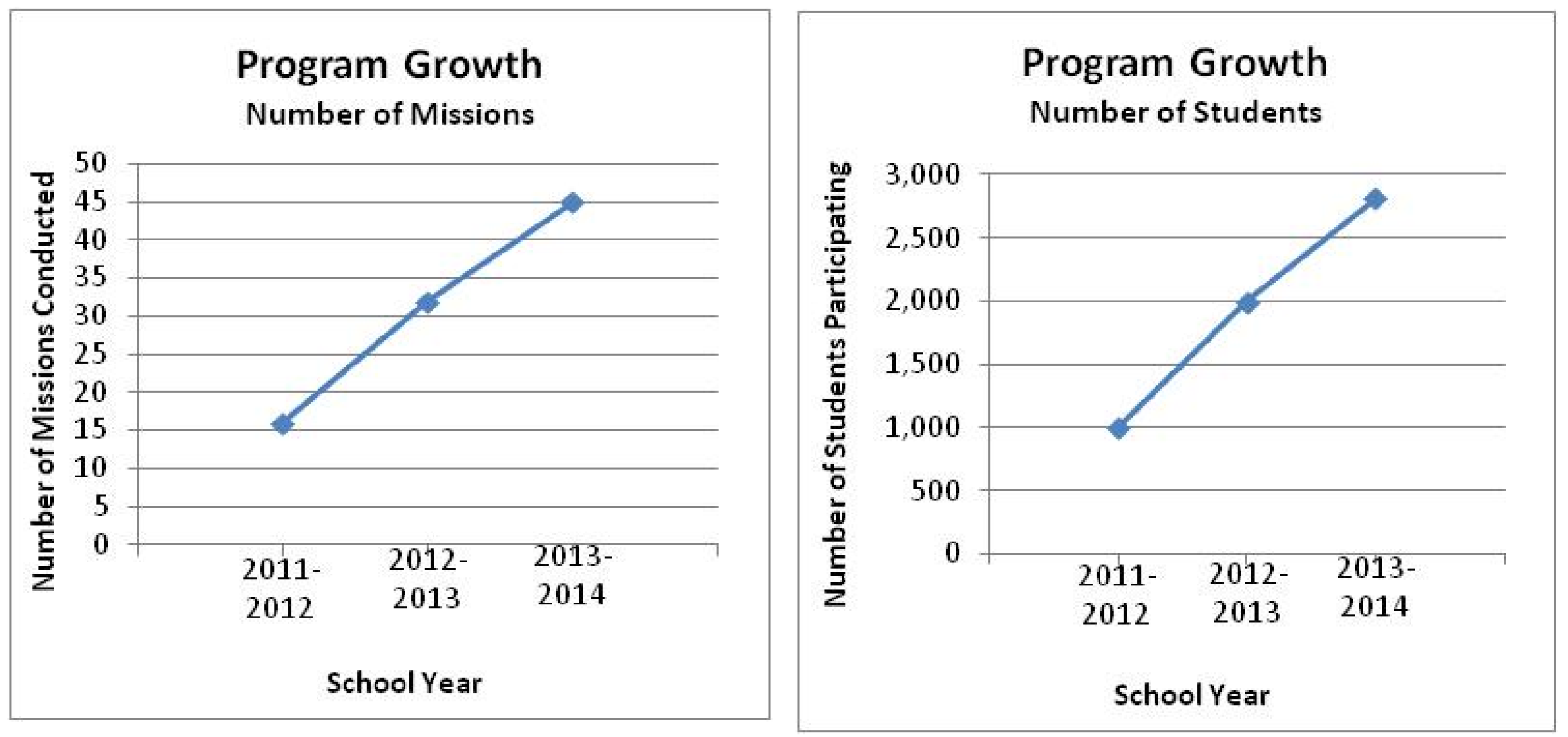

- Hope is to eventually expand this program across the country. Development of a broad dissemination plan is part of the grant. 


\section{NAsA 47 Challenger Learning Centers}

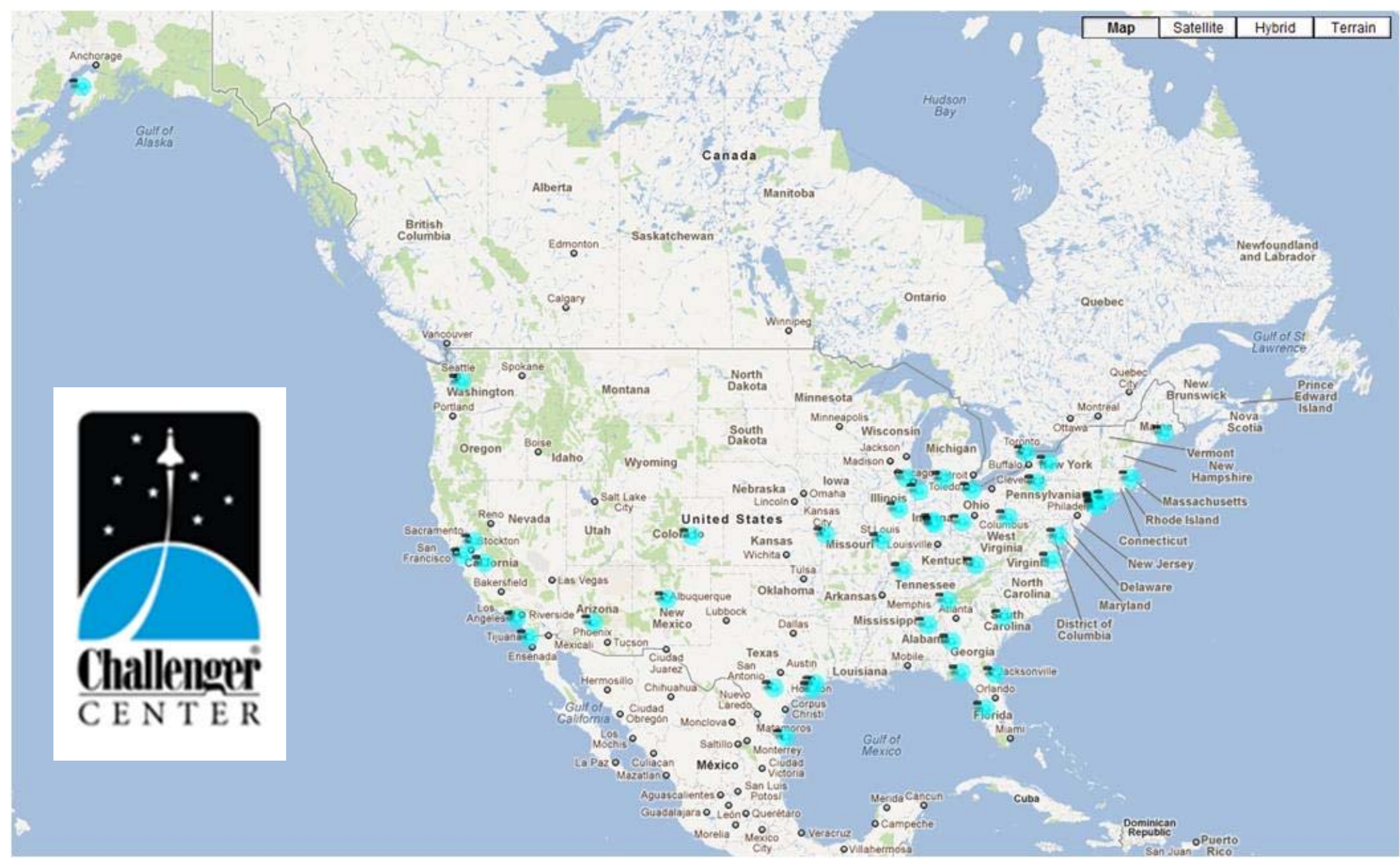




\section{NAsA NASA Center Outreach Responsibilities}

- At some point the current partner centers will reach their capacity to supply experts, but there are other NASA centers, and plenty of commercial companies supporting our nations space program whose work has the capability to inspire.

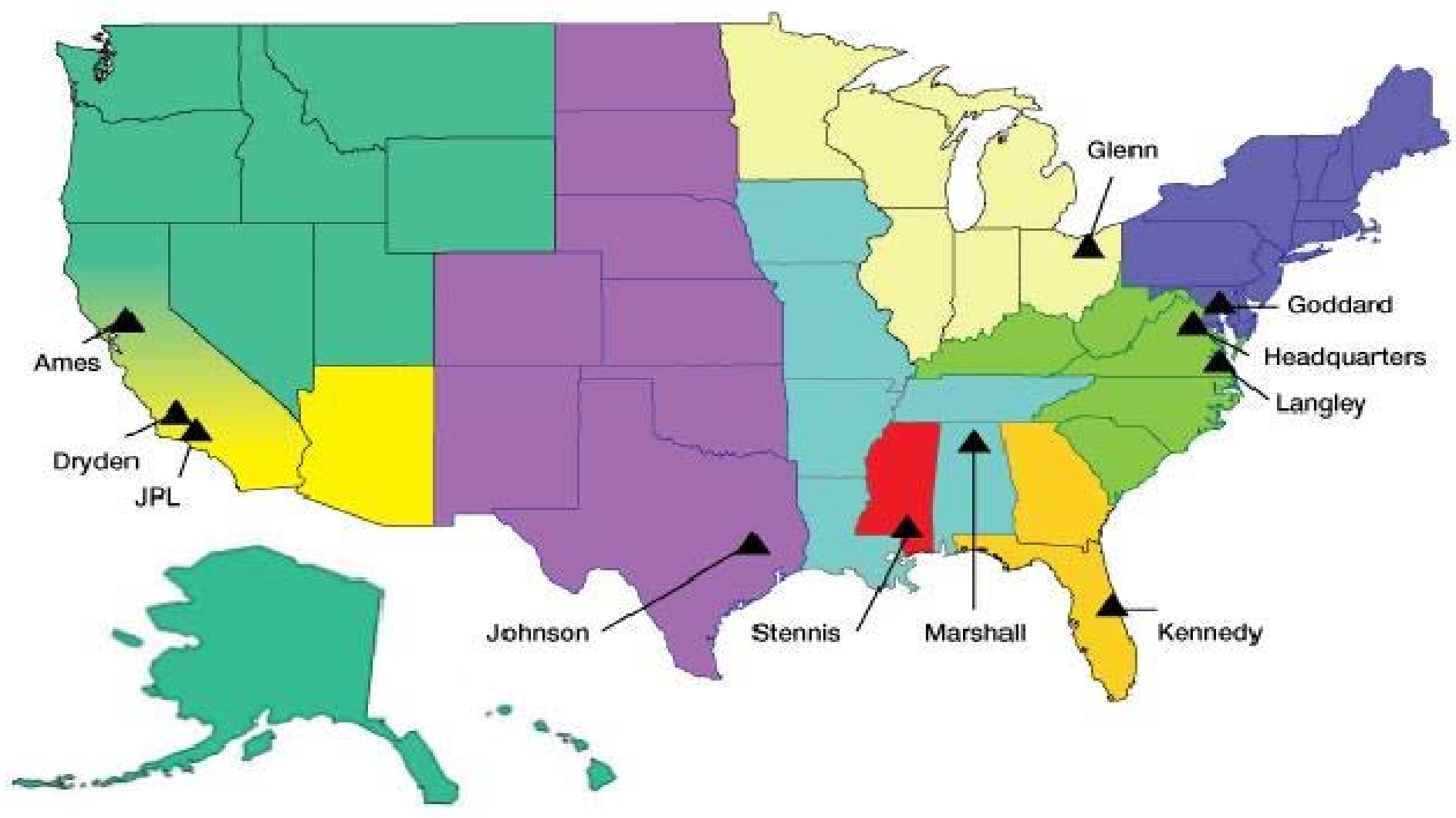




\section{NAsA Taking our stories home}

- If you don't have a program like Mission to Mars in your area, consider reaching out to your hometown via videoconference

- 27 people in MSFC's Advanced Concepts Office can reach 15 states just by volunteering to support their hometowns

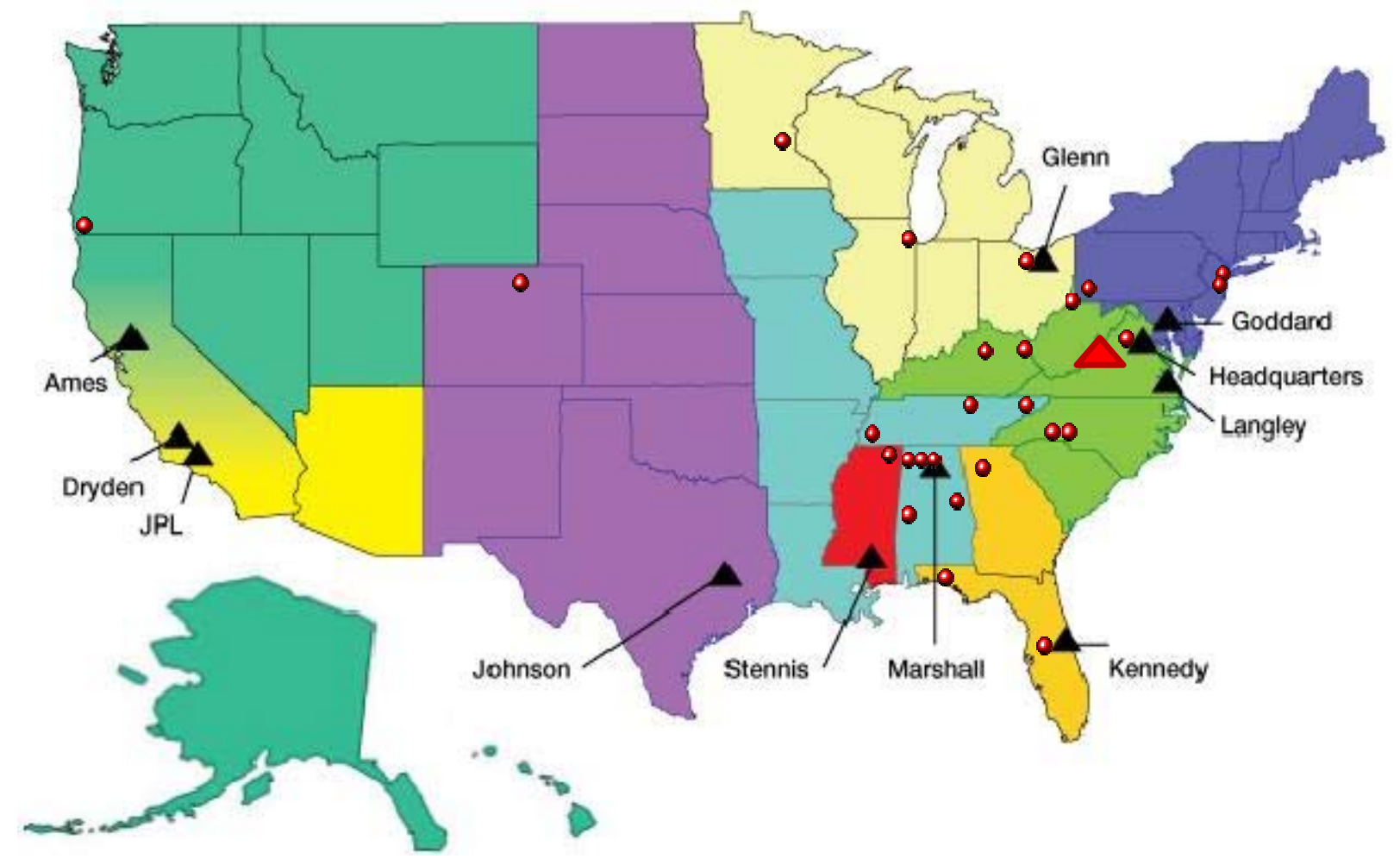


NASA The Students
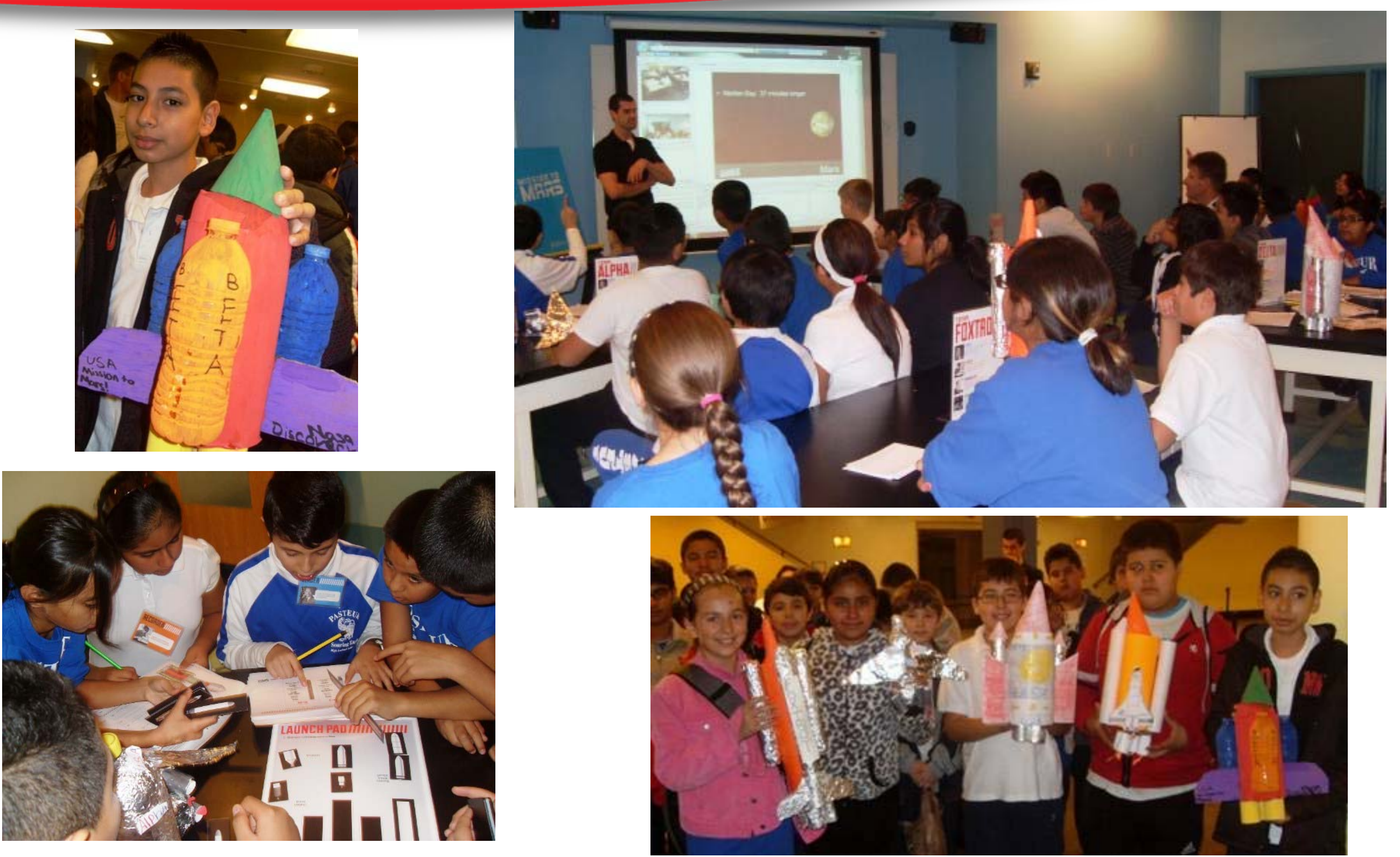
What are the top 3 dangers working at NASA?

- Do you get to see your families?

- How long do you work (the hours)?

- Do you ever have to add parts to a rocket to make it work?

- Do you have to worry where the parts of the rocket will fall?

- How long does it take to build a rocket?

- Do you use telescopes and/or satellites to observe planets? And if so, are they linked to share information all over the world from space?

- Would NASA use quantum physics within their research?

- Has NASA thought about exploring Pluto?

Would you happen to know how gravity works? 


\section{NASA}

\section{Back up \\ BACK UP}




\section{Project Goals}

- Implement new educational linkages via an interactive videoconferencing platform between MSI, a major inner city public school district, schools serving low income rural and suburban middle school students, and, initially, two Challenger Learning Centers (CLCs).

- Design, evaluate, and launch three programs that showcase research at NASA Centers.

- Promote learning about NASA's space missions and enrich middle school curricula with experiences and challenges that inspire youth to pursue careers in NASA-related STEM.

- Develop a broad dissemination plan with assistance from CLC National to distribute all materials regionally and nationwide and promote project replication among science centers, CLCs, school districts, NASA Centers, and other institutions of informal education. 


\section{SHROUD/PAYLOAD IIIIIIIIIIIIIIIIIIIIIIIII}

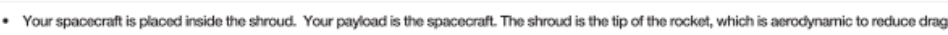

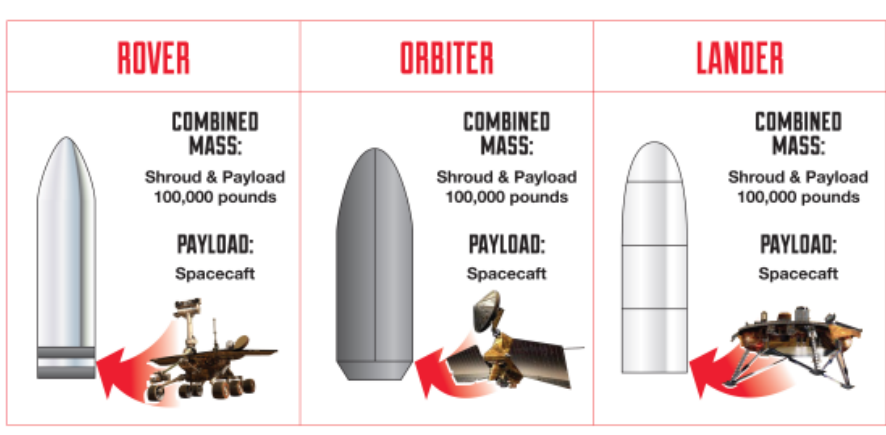

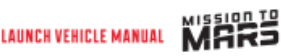

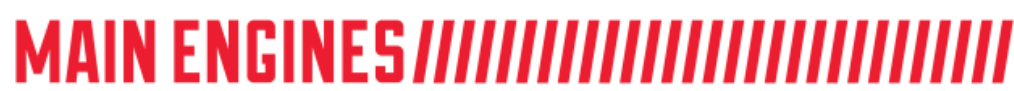

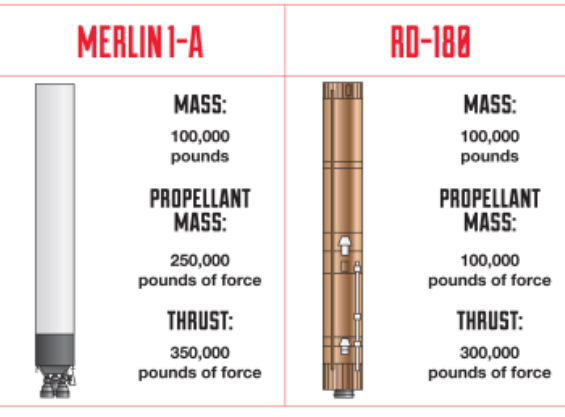

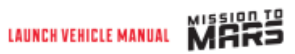

\section{UPPER STAGE ENGINES /IIIIIIIIIIIIIIIIII|}

- The upper stage engine provides thust when the rocket is in outer space., It will send the rocket to Mars

\begin{tabular}{|l|l|l|}
\hline HLLIBB-? & MERLIN I-C & RL-IOA \\
\hline
\end{tabular}

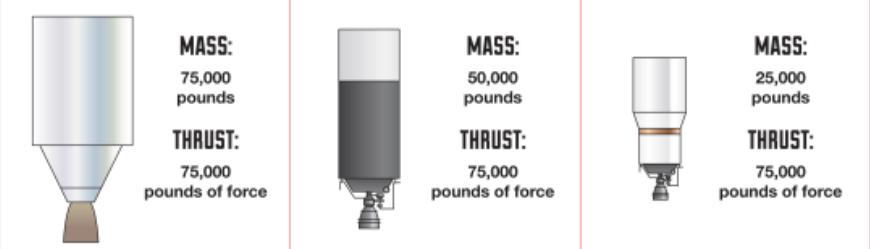

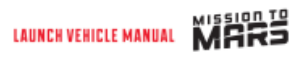

\section{BODSTER ENGINES IIIIIIIIIIIIIIIIIIIIIIIIII}

\begin{tabular}{|c|c|c|c|c|}
\hline GEMG8 & \multicolumn{2}{|c|}{ MERLIN1-D } & \multicolumn{2}{|c|}{ AERDJETS S月B'S } \\
\hline $\begin{array}{l}\text { COMBINED } \\
\text { MAS5: } \\
75,000 \\
\text { pounds }\end{array}$ & $A \cap$ & $\begin{array}{l}\text { COMBINED } \\
\text { MASS: } \\
30,000 \\
\text { pounds }\end{array}$ & An & $\begin{array}{l}\text { COMBINED } \\
\text { MASS: } \\
50,000 \\
\text { pounds }\end{array}$ \\
\hline $\begin{array}{c}\text { COMBINED } \\
\text { THRUST: } \\
150,000 \\
\text { pounds of force }\end{array}$ & 롤료 & $\begin{array}{c}\text { COMBINED } \\
\text { THRUST: } \\
50,000 \\
\text { pounds of force }\end{array}$ & & $\begin{array}{c}\text { COMBINED } \\
\text { THRUST: } \\
60,000 \\
\text { pounds of force }\end{array}$ \\
\hline
\end{tabular}

\section{Mำ}


- MSFC helps to develop and refine content for the launch vehicle design exercise. Supplied launch vehicle performance characteristics, and videos and animations of launches.

- MSFC provides subject matter experts for participation in videoconference with students, a 30min interaction with 3 experts each time.

- MSFC has 14 volunteer experts, average commitment last year was less than 1 hour for each. Not a burdensome commitment. 